\title{
Human Factors Analysis to Improve the Processing of Ares-1 Launch Vehicle
}

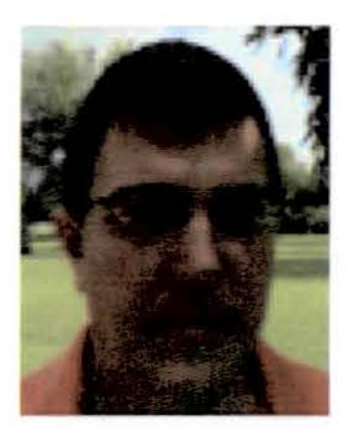

Damon B. Stambolian NASA Kennedy Space Center (KSC) Engineering and Technology Directorate 


\section{Problem Introduction}

- Flight vehicle engineering designers for Ares-1 launch vehicle:

- had the challenge to design the flight vehicle for effective, efficient and safe ground operations

- needed to comply with the Human Systems Interface Requirements for ground processing of flight hardware 


\section{Solution}

- Solution was to build a physical mockup of the areas where ground operations take place

- Determine the human interfaces and associated tasks performed

- Determine the applicable requirements for these interfaces and tasks

- Used the mockup to practice modifications to the design to meet the human factors requirements

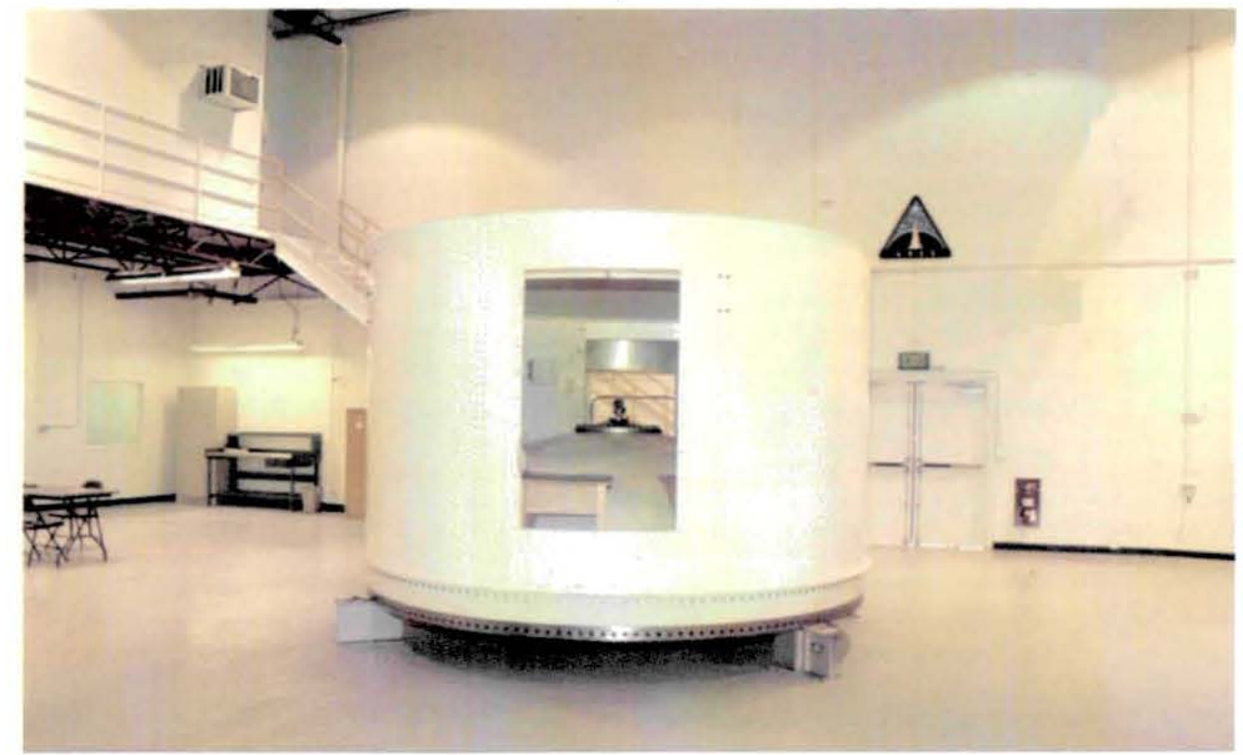




\section{Solution - Requirements}

- The ground maintenance and assembly requirements in the HSIR included human factors major concerns for:

- hardware access

o work envelopes volumes

- reach envelope volumes

- visual access

- LRU weight limit

- tool clearances

○ appropriate clothing and equipment

- emergency egress

- maintenance without damage 


\section{Solution - Requirements}

- The Ares key human operations:

- Ground handling and access platforms for all areas needed for access to the flight components

- Avionics box installation/removal inside vehicle

- Translation of avionics boxes from inside vehicle through hatch

- Work volume inside skirt with multiple technicians

- Installation/Removal of ground support equipment in vehicle

- Normal and Emergency Egress operations through hatch and inside skirt 


\section{Example - Ground Support Equipment}

- There is little that can be done to change these cramped dimensions in rocket design, so adjustments were made to:

$\circ$ the ground support equipment

- box placement locations and heights

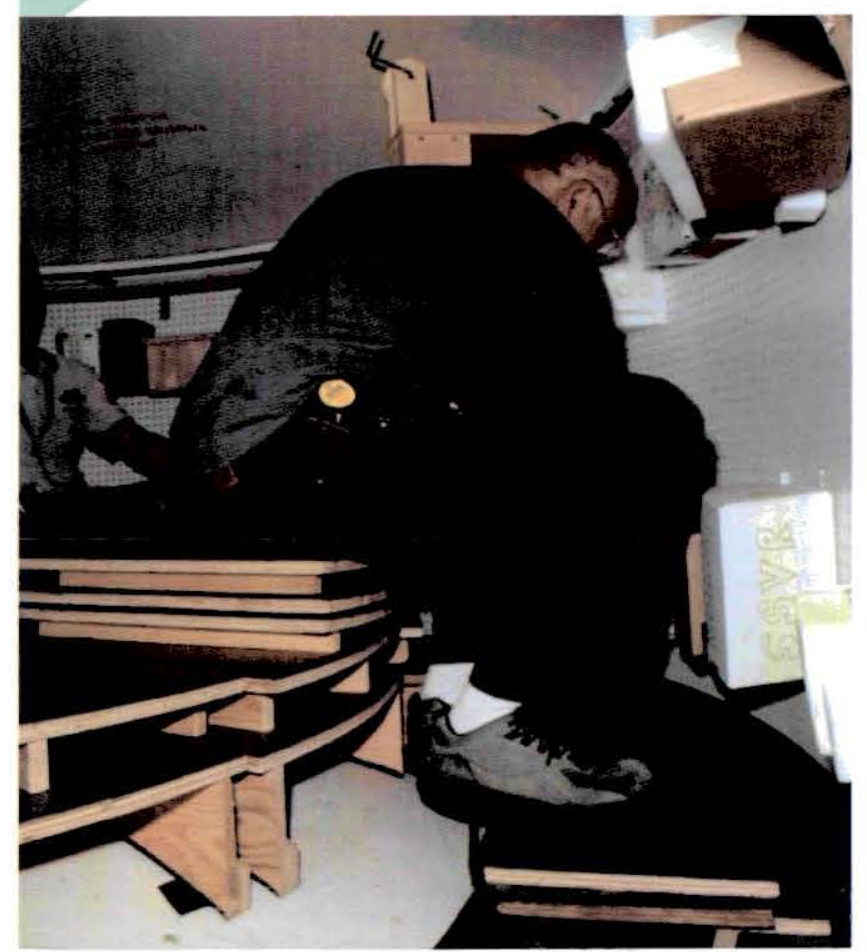

- The ground support equipment acts as a seat, and foot rest.

- Ground support equipment installed to:

- protect the technician from injury

- protect the flight hardware from damage 


\section{Example - Avionics Boxes}

- There were several avionics boxes.

- The analysis determined the best locations based on the technicians location capabilities and:

- Box weight

- Tool access

- Hand volumes

- Cable routes

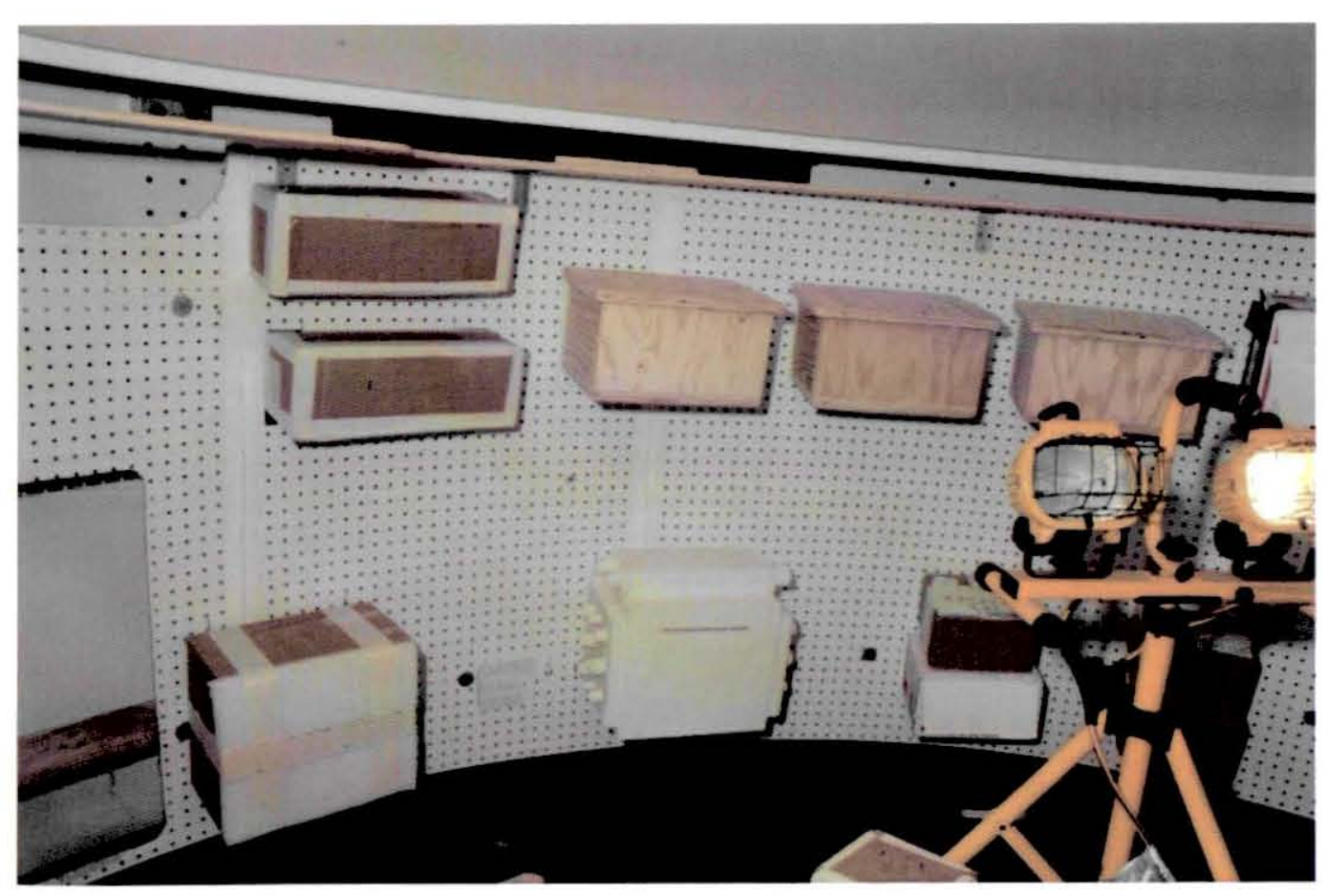




\section{Example - Hatch}

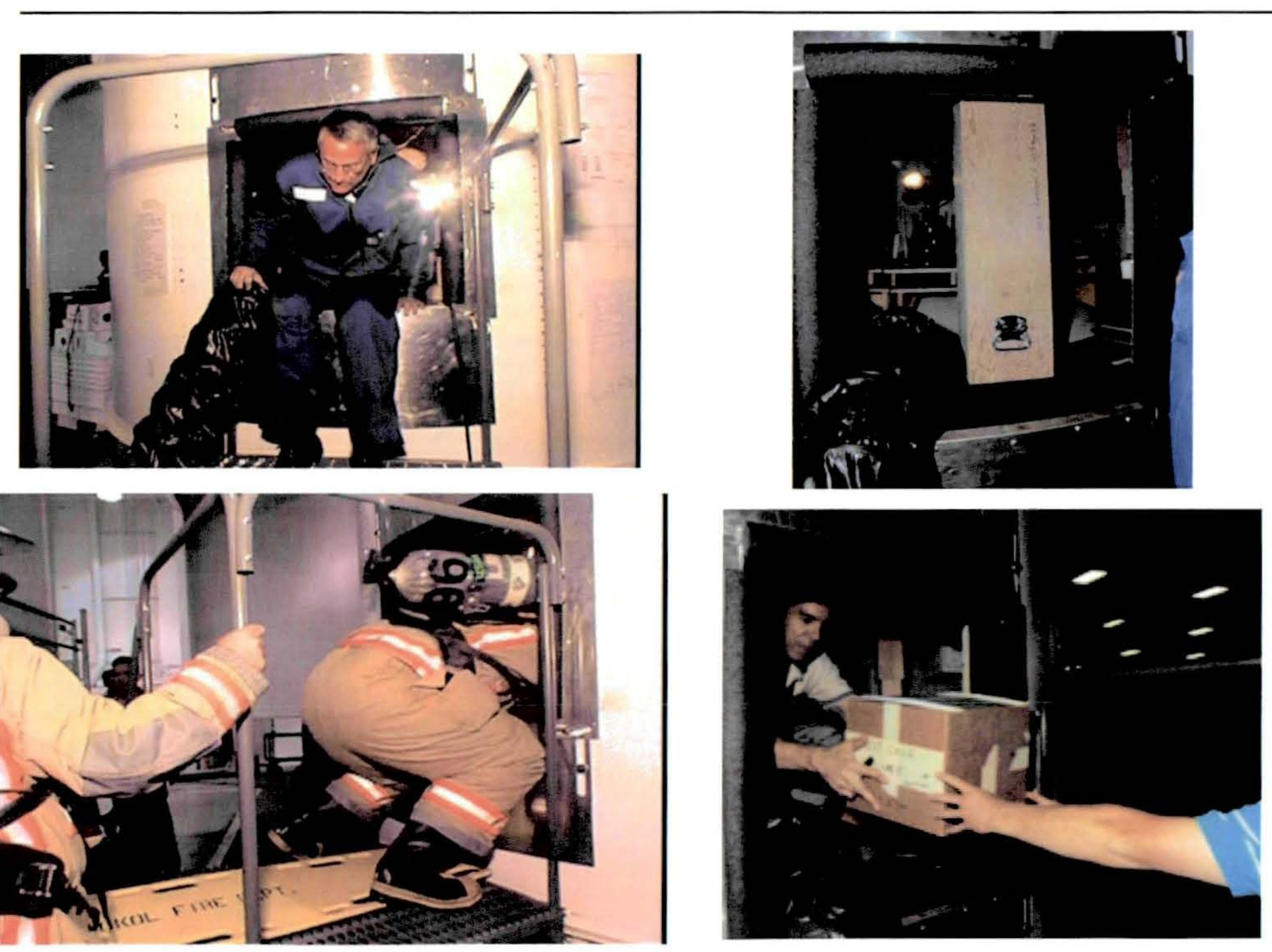




\section{Advantages and Disadvantages}

- The physical mockup is very close to the real working environment

- Allow for the differences in human movement

- Promotes collaboration between designers and operators

- Different ways to perform a task can be analyzed and can be videotaped for further analysis
- Takes longer to build, and are more expensive than computer models

- Take up space, not easy to transport

- There is a chance of someone getting injured

- Operators may need to travel to the physical mockup location

- Finding the best solution takes time. Videos do not capture the 3D perspective 


\section{Suggested Applications}

Use physical mockups

- To improve communication between designers and users

- Where there are multiple activities taking place in the same area

- Where there are more than one person working in the same area

- Where there are awkward positions that cannot be understood well in computer models

- Where there are many human factors scenarios. To make the most of the cost and time spent to build the mockup 


\section{Recommendations}

- Promote more standardized and integrated mockup processes and designs between KSC, MSFC, and JSC

- Promote sharing of mockups across Centers and projects

- Embed mockup analysis as part of the Engineering processes, as one option to choose from for the appropriate human factors engineering analysis

- Future mockups should also include more collaboration with the ground support equipment

- Introduce motion capture analysis capabilities into mockup activities. Motion capture allows for quicker and simpler physical mockups

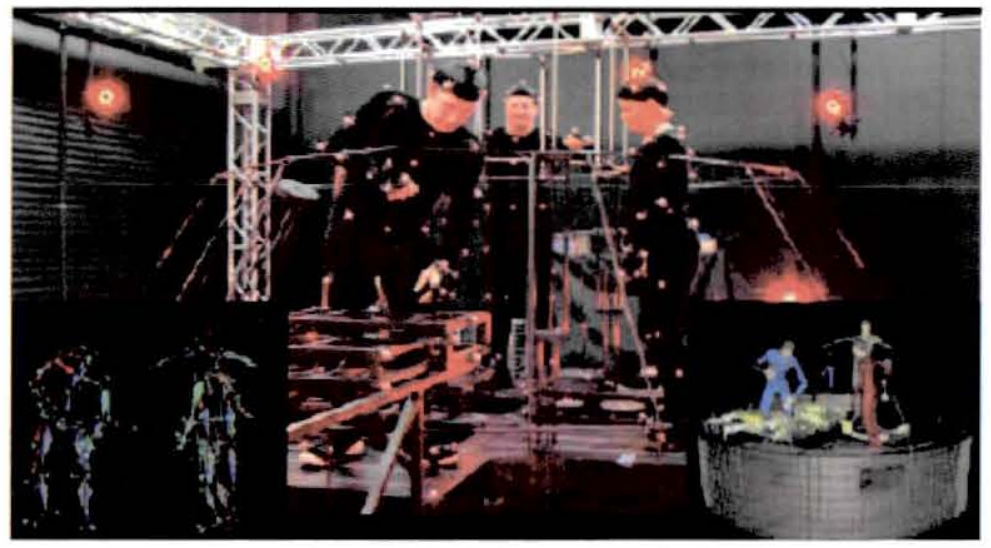




\section{Summary}

- Mockup analysis proved very effective to promote collaboration between Ares - 1 designers and ground operations personal to improve the flight hardware design

- Continue using mockups analysis to promote human factor design collaborations and solutions 